\title{
Arterial Pressure, Cardiac Output and Systemic Resistance before and after Pithing in Normotensive and Spontaneously Hypertensive Rats
}

\author{
By
}

\author{
I. Albrecht, ${ }^{1}$ M. Hallbäck, S. Julius, ${ }^{2}$ Y. Lundgren, L. Stage, \\ L. WeIss and B. Folkow \\ Received 10 January 1975
}

\begin{abstract}
Albrecht, I., M. Hallbäck, S. Julius, Y. Lundgren, L. Stage, L. Weiss and B. Folkow. Arterial pressure, cardiac output and systemic resistance before and after pithing in normotensive and spontaneously hypertensive rats. Acta physiol. scand. 1975. 94. 378-385.

After complete cardiovascular denervation mean arterial pressure (MAP) falls to almost equally low levels in spontaneously hypertensive rats (SHR) and normotensive control rats (NCR). This has earlier been suggested to indicate a dominance of neurogenic mechanisms in established SHR hypertension. - In the present study, total peripheral resistance (TPR) remains, however, some 35 per cent higher in adult SHR than in NCR after pithing while cardiac output (CO), and stroke volume, is 35 per cent lower in SHR. These opposite differences in TPR and CO after denervation, resulting in equal MAP levels in SHR and $\mathrm{NCR}$, seem rather to be a consequence of the rapidly established structural adaptation that affects all SHR high-pressure cardiovascular sections. Thus, the SHR precapillary resistance vessels display thickened walls and luminal narrowing, which keeps TPR higher than in NCR even during maximal vasodilatation. Due to hypertrophy, the SHR left ventricle exhibits a reduced myocardial stretch for a given filling pressure and stroke volume is consequently reduced more than in NCR after complete denervation. Paradoxically, therefore, rather than reflecting any dominance of neurogenic mechanisms in established SHR hypertension the MAP equalization in SHR and NCR after cardiovascular denervation emphasizes the hemodynamic importance of cardiovascular structural changes present in hypertension.
\end{abstract}

Abstract

Many studies (e.g., Okamoto 1969, Clark 1971, Nosaka et al. 1972) indicate that neurohormonal influences are of great importance for the initiation of high blood pressure in genetically hypertensive rats of the Okamoto strain (SHR) and the Smirk strain (GHR). Further, since elimination of all sympathetic influences by pithing or by ganglionic blockade nearly abolishes the difference in mean arterial pressure (MAP) between adult SHR and normotensive control rats (NCR) (e.g., Okamoto 1969, Shibayama, Mizogami and Sokabe

\footnotetext{
1 Inst. of Physiology, Czechoslovak Academy of Sciences, Praha; guest research scientist of the Royal Academy of Sciences, Sweden.

2 On sabbathical leave; Dept. of Medicine, Univ, of Michigan, Ann Arbor, Mich. USA.
} 
1971, Iriuchijima 1973), it is often assumed that the increased resistance is maintained almost solely by neurogenic mechanisms also in the "established" phase of SHR hypertension.

Since, however, MAP is a product of cardiac output $(\mathrm{CO})$ and total peripheral resistance (TPR), the true significance of the pressure fall subsequent to complete cardiovascular denervation can be evaluated only if both the CO and TPR components are known. In fact, perfusion experiments reveal that resistance is higher in established SHR hypertension than in NCR even during maximal vasodilatation (Folkow et al. 1970), reflecting the presence of hemodynamically important structural changes of the SHR resistance vessels ( $c f$. Folkow et al. 1973, 1974). Furthermore, studies on isolated perfused SHR hearts show that they display a smaller stroke volume than NCR hearts at a given diastolic filling pressure, mainly due to the left ventricular hypertrophy in SHR and the consequent decrease in average myocardial diastolic stretch (Hallbäck, Isaksson and Noresson 1975).

Against such a background there are good reasons to believe that TPR may be elevated but $\mathrm{CO}$ decreased after denervation in SHR inspite of a "normalized" blood pressure, compared with equally treated NCR. It was therefore decided to study more precisely the relationship between MAP, CO, and TPR after complete cardiovascular denervation by means of pithing in SHR and NCR.

\section{Methods}

30 6-7 months old SHR, body weight ranging between 300 to $370 \mathrm{~g}$, and 30 age-, sex- and weight-matched NCR were used. After anesthesia with Inactin ${ }^{\circledR}$ (5-aethyl-5 (1-metyl-propyl)-2 thiobarbituric acid; Promonte), $100 \mathrm{mg} / \mathrm{kg}$ b.wt., a cannula was introduced into the aortic arch via the carotid artery. The cannula was connected to a pressure transducer and a Grass polygraph for recordings of blood pressure and heart rate and subsequently used for withdrawal of arterial samples. One jugular vein was cannulated by a PE 10 catheter, the tip of which was placed close to the heart. The trachea was cannulated and the animals were artificially ventilated at a rate which barely suppressed spontaneous respiration. A rythmic inflation was used with a peak pressure of 9-10 $\mathrm{cm} \mathrm{H}_{2} \mathrm{O}$, which was equally maintained in all animals before and after pithing. It should here be noted that the positive pressure breathing tends to reduce $\mathrm{CO}$ by impediment of venous return, particularly after cardiovascular denervation. Flaxedil, $1 \mathrm{mg} / 100 \mathrm{~g}$ was given i.p. to suppress spontaneous motility and seizures in combination with the pithing procedure. Pithing was performed by introducing a $2 \mathrm{~mm}$ steel rod from the atlanto-occipital joint down the entire spinal canal to destroy the spinal medulla, thereby eliminating all sympatho-adrenal activity.

$\mathrm{CO}$ was measured either by 1$)$ the radioactive rubidium $\left({ }^{8} \mathrm{Rb}\right)$ injection technique, whereby also an approximate estimation of CO distribution may be obtained (Sapirstein 1958), or by 2) the cardiogreen dye dilution technique, as modified for rats.

1) $C O$ measurement with the ${ }^{86} R b$ technique was performed on 20 SHR and 20 NCR. 10 pairs were used before and 10 pairs after the standardized pithing procedure. When pressure and heart rate were stabilized, the arterial cannula was connected to an oil-filled, constant speed withdrawal system. Exactly $20 \mu \mathrm{Ci}$ of ${ }^{86} \mathrm{Rb}$ was quickly injected by a step dispenser syringe $(0.1 \mathrm{ml})$ into the jugular catheter. After the ${ }^{86} \mathrm{Rb}$ injection, carotid arterial blood was withdrawn at a constant speed of $0.67 \mathrm{ml} / \mathrm{min}$ over exactly $10 \mathrm{~s} .50$ $\mathrm{s}$ later the animal was suddenly killed by an i.v. injection of $0.4 \mathrm{ml}$ concentrated $\mathrm{KCl}$ solution.

For CO determination the radioactivity in the $10 \mathrm{~s}$ arterial sample was counted by means of a $\gamma$-counter. Number of counts in weighed samples of kidneys, heart, skeletal muscle, skin and liver were used to approximate blood flow through these test organs. Even though the total ${ }^{86} \mathrm{Rb}$ amount does not enter the intracellular "sink" of the respective tissues during the first passage, there is no reason to assume that the amount of trapping in different animals groups would be different. Thus, this technique allows a fair estimation also of $\mathrm{CO}$ distribution in experimental animals. The ${ }^{86} \mathrm{Rb}$ method has, however, the obvious disadvantage of allowing only one $\mathrm{CO}$ measurement per animal. Consequently, measurements were first performed on one pair of SHR and NCR with intact sympathetic control, followed by another pair in which the measurements were performed during steady state condition after pithing. 
2) CO measurements with the dye dilution technique allowed multiple determinations in each animal and therefore only 10 SHR and 10 NCR were used. At least two measurements were performed both before and after pithing. Subsequent to the two measurements after pithing, most of the rats received papaverine, $0.5 \mathrm{mg} / \mathrm{kg}$, in order to ensure maximal vasodilatation prior to a final $\mathrm{CO}$ measurement.

By means of a step dispenser syringe $0.04 \mathrm{ml}$ of cardiogreen solution was injected into the jugular vein. Arterial blood (maximally $0.35 \mathrm{ml}$ per recording) was withdrawn at a constant speed $0.67 \mathrm{ml} / \mathrm{min}$, passing through a specially designed low volume $(0.05 \mathrm{ml})$ densitometer cuvette. After the determination the blood was reinfused. The densitometer cuvette was connected to a Servogor recorder for recording of the dye dilution curve.

Calibration of the densitometer was performed with known concentrations of dye diluted in human plasma, and the system was linear over the range of the recording scale. The accuracy of the dye dilution determinations was checked against actual plasma flows in a tube system with a mixing chamber and a pump, delivering constant flows from $10 \mathrm{up}$ to $90 \mathrm{ml} / \mathrm{min}$. This check revealed a linearly increasing overestimation of the flow with the dye dilution technique as compared to the actual flow in the system, being maximally 9 per cent at flow rates of $90 \mathrm{ml} / \mathrm{min}$. For calculating $\mathrm{CO}$ from the dye dilution recordings, a digitizer unit connected to a Hewlett-Packard calculator was used.

\section{Results}

Mean arterial pressure (MAP) in SHR, $198 \pm 4 \mathrm{~mm} \mathrm{Hg}$, was significantly higher than in NCR $132 \pm 4 \mathrm{~mm} \mathrm{Hg}(\mathrm{p}<0.001)$, these pressure levels being somewhat above the usual since the carotid artery cannulation implies a partial baroreceptor unloading. Table I presents mean values of cardiac output (CO), total peripheral resistance (TPR) and heart rate (HR) before and after pithing, the former two parameters being expressed per $100 \mathrm{~g}$ of b.wt. There was no appreciable difference in $\mathrm{CO}$ values obtained by the two methods and the results are therefore pooled in the Table. During the prevailing experimental conditions, involving artificial positive pressure ventilation and unilateral carotid occlusion by

TABLE I. Mean arterial pressure (MAP), cardiac output (CO), total peripheral resistance (TPR) and heart rate (HR) before and after pithing in SHR and NCR. Values presented are expressed as means \pm S.E. Levels of significance and per cent difference between SHR and NCR are given below. $* * *$ indicates significant difference $(\mathrm{p}<0.001)$ from control situation.

\begin{tabular}{|c|c|c|c|c|c|c|c|c|}
\hline & \multicolumn{4}{|c|}{ Control conditions } & \multicolumn{4}{|c|}{ After pithing } \\
\hline & $\begin{array}{l}\text { MAP, } \\
\mathrm{mm} \mathrm{Hg}\end{array}$ & $\begin{array}{l}\mathrm{CO} \\
\mathrm{ml} / \mathrm{min} \times \\
100 \mathrm{~g}\end{array}$ & $\begin{array}{l}\text { TPR, } \\
\text { PRU/ } \\
100 \mathrm{~g}\end{array}$ & $\begin{array}{l}\text { HR, } \\
\text { beats/ } \\
\text { min }\end{array}$ & $\begin{array}{l}\text { MAP, } \\
\mathrm{mm} \mathrm{Hg}\end{array}$ & $\begin{array}{l}\mathrm{CO}, \\
\mathrm{ml} / \mathrm{min} \times \\
100 \mathrm{~g}\end{array}$ & $\begin{array}{l}\text { TPR, } \\
\text { PRU/ } \\
100 \mathrm{~g}\end{array}$ & $\begin{array}{l}\text { HR, } \\
\text { beats/ } \\
\text { min }\end{array}$ \\
\hline $\begin{array}{l}\text { SHR } \\
\mathrm{n}=\mathbf{2 0}\end{array}$ & $198 \pm 4$ & $18.9 \pm 1.0$ & $11.0 \pm 0.6$ & $348 \pm 7$ & $40 \pm 2 * * *$ & $9.2 \pm 0.9^{*}$ & $4.9 \pm 0.4^{*}$ & * $269 \pm 9 * * *$ \\
\hline $\begin{array}{l}\text { NCR } \\
n=20\end{array}$ & $132 \pm 4$ & $24.0 \pm 0.9$ & $5.6 \pm 0.2$ & $358 \pm 9$ & $44 \pm 2 * * *$ & $14.1 \pm 0.9 *$ & * $3.6 \pm 0.3 *$ & $* 263 \pm 6 * * *$ \\
\hline $\begin{array}{l}\text { Level of sign } \\
\text { difference } \\
\text { SHR-NCR }\end{array}$ & $\mathrm{p}<0.001$ & $1 \mathrm{p}<0.001$ & $\mathrm{p}<0.001$ & n.s. & n.s. & $\mathrm{p}<0.001$ & $\mathrm{p}<0.01$ & n.s. \\
\hline $\begin{array}{l}\text { Per cent } \\
\text { difference } \\
\text { SHR-NCR }\end{array}$ & $+51 \%$ & $-21 \%$ & $+87 \%$ & - & - & $-35 \%$ & $+36 \%$ & - \\
\hline
\end{tabular}


Fig. 1. 1llustrates the fall in arterial pressure (left part), cardiac output (CO) (middle part) and total peripheral resistance (TPR) (right part) before and after pithing in SHR and NCR. Vertical bars indicate $\mathbf{S . E}$.
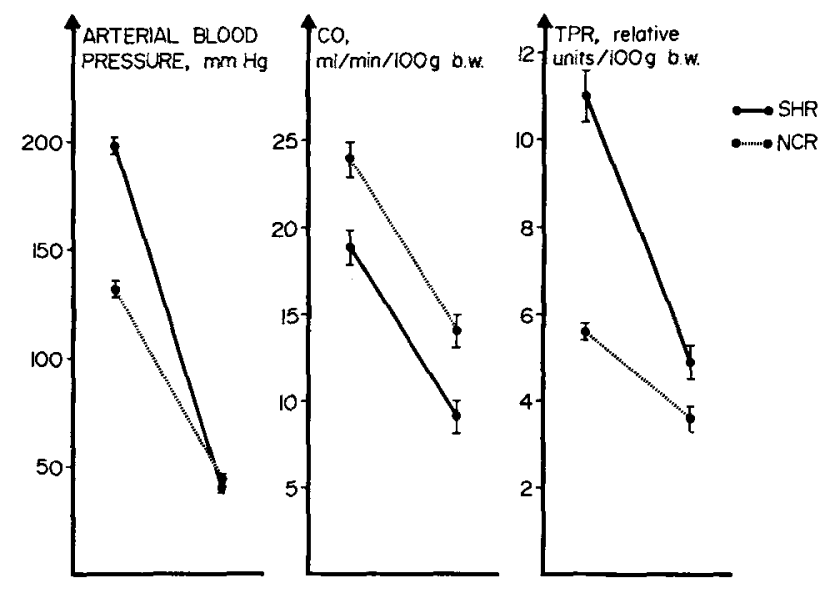

the arterial cannulation, CO was about $20 \%$ lower in SHR than in NCR in the control "resting" state $(p<0.001)$ while TPR was nearly twice as high in SHR as in NCR $(p<0.001)$.

After pithing the arterial pressures fell to about equally low levels in the NCR and SHR groups. The $\mathrm{CO}$ difference was even more pronounced after pithing, $\mathrm{CO}$ being some 35 per cent lower in SHR than in NCR $(p<0.001)$, the same being true for stroke volume since HR were about the same. In return, TPR was now about 35 per cent higher in SHR compared with NCR $(\mathrm{p}<0.01)$. It should be noted that after pithing, eliminating neurogenic cardiovascular control and drastically lowering pressure, vascular smooth muscle tone was virtually eliminated, as checked by injection of papaverine which did not appreciably further reduce TPR from the postpithing values. Therefore the systemic vascular beds of NCR and SHR could be considered maximally dilated in the prevailing situation, and TPR is then only dependent on the structural design of the resistance vessels and on the transmural pressures, which were largely equal in NCR and SHR. - The results are also presented in a diagrammatic form in Fig. 1.

In the group of SHR and NCR studied with the cardiogreen technique the percentual fall in $\mathrm{CO}$ as a result of pithing could be determined in each animal. Compared with NCR a modestly, though significantly greater CO reduction was observed in the SHR group (p < 0.05 ), where $\mathrm{CO}$ was reduced by $63 \pm 5$ per cent upon pithing while the $\mathrm{CO}$ reduction in NCR was $54 \pm 2$ per cent.

Measurements of blood flow distribution in SHR and NCR by the ${ }^{86} \mathrm{Rb}$ technique revealed that before pithing the cutaneous and renal blood flows were somewhat lower in SHR, while in skeletal muscle, myocardium and liver the flow was about equal in SHR and NCR. This general pattern also prevailed after pithing, even though the muscle blood supply appeared to increase modestly in both groups.

In summary, even after pithing and papaverine administration TPR was some 35 per cent higher in SHR than in NCR while CO, and stroke volume, was about 35 per cent lower in SHR. Consequently MAP reached about the same low levels in SHR and NCR when all nervous influences on the cardiovascular system were abolished. 


\section{Discussion}

The importance of the cardiovascular neurohormonal control system for the initiation and maintenance of high blood pressure in genetically hypertensive rats of the Okamoto strain (SHR), and also of the Smirk strain (GHR), has been repeatedly emphasized (e.g. Okamoto 1969, Smirk 1970, Nosaka et al. 1972) and many studies provide evidence of an increased neurohormonal discharge in SHR ( $c f$. Okamoto 1969). Further, also young "prehypertensive" SHR display an inherent, evidently genetically linked hyperreactivity of central autonomic structures, resulting in exaggerated increases of heart rate and arterial pressure compared with NCR, whenever enhanced alertness is displayed or when the rats are exposed to "mental stress" in their daily life (Hallbäck and Folkow 1974). Moreover, the effects of immunosympathectomy in newborn GHR and SHR (Clark 1971, Folkow et al. 1972), the beneficial effects of early treatment with sympathicolytic drugs (Weiss 1974, Weiss, Lundgren and Folkow 1974) and of longterm reduction of normal environmental stimuli (Hallbäck 1975) strongly suggest that central neurohormonal mechanisms are of crucial importance for the very initiation of hypertension in these animal models of human essential hypertension ( $c f$. Folkow 1975).

Against such a background the finding that almost equally low arterial pressure levels are reached in SHR and NCR after complete cardiovascular denervation has often led to the apparently logical suggestion that the increased pressure in SHR must be essentially the result of an increased sympathetic activity, also in the established phase of hypertension (Okamoto 1969, Shibayama, Mirogami and Sokabe 1971). However, arterial pressure depends not only on total peripheral resistance (TPR) but also on cardiac output (CO). Consequently, a recording only of the product of these two parameters, i.e. of mean arterial pressure (MAP), does not allow any conclusions concerning the mechanisms behind the pressure fall after autonomic blockade. Iriuchijima (1973) recently measured both MAP and $\mathrm{CO}$ before and after ganglionic blockade in 9 pairs of SHR and NCR, which were younger (as an average 17 weeks old) than the present ones. As in the present study, arterial pressures reached about equally low levels after denervation, TPR appeared to be higher in SHR than in NCR, although no statistical significance was obtained, possibly because of the fairly small material.

The present results were obtained on a much larger experimental material and two different techniques for $\mathrm{CO}$ measurements were used, which did not mutually differ to any significant extent. After pithing, $\mathrm{CO}$ was found to be about 35 per cent lower in SHR than in NCR $(p<0.001)$ and the same was true for stroke volume since heart rates were largely the same. In return, TPR was largely 35 per cent higher in SHR $(\mathrm{p}<0.01)$ so that MAP was about equal in NCR and SHR. Before these results are further considered, the methods used for $\mathrm{CO}$ measurement will be briefly evaluated. The ${ }^{8 \theta} \mathrm{Rb}$ technique may be slightly influenced by the modest recirculation that occurs, even though this tracer is to a marked degree "trapped" in the tissues during its first circulation. This technique will also tend to overestimate very low flow values, since the standardized sampling period was relatively short $(10 \mathrm{~s})$, and it will further not allow for extrapolations as will the cardiogreen technique. Therefore the $\mathrm{CO}$ values after pithing may, if anything, be slightly overestimated, 
and the TPR ones correspondingly underestimated, especially in SHR where CO was then particularly low.

A possible disadvantage of the cardiogreen method would be the unavoidable and slightly larger blood loss during each arterial sampling $\left(0.35 \mathrm{ml}\right.$, at most) compared with the ${ }^{86} \mathrm{Rb}$ technique. However, this blood loss corresponds to only some 1.5 per cent of the total blood volume in rats of this size. Neither heart rate nor pressure revealed any significant cardiovascular influence of this small blood withdrawal which was, moreover, quickly reinfused to the animal. Therefore, the $\mathrm{CO}$ methods used seem to be satisfactory for the present purpose.

A standardized positive pressure ventilation was, as mentioned, maintained under identical circumstances in SHR and NCR throughout the experiments. Such artificial respiration is likely to induce cardiovascular reflexes by the impediment with venous return, which tends to reduce enddiastolic filling pressure. Such interferences, not present during normal conditions, might to a different extent influence CO in NCR and SHR. Thus, control CO was about 20 per cent lower in SHR than in NCR in the prevailing situation, while no such difference is found when anesthetized SHR and NCR are compared without artificial respiration (own preliminary results).

After spinal destruction, eliminating all cardiovascular reflex adjustments, the systemic vessels became virtually maximally dilated, as checked by papaverine. TPR is in this situation essentially determined by the structural design of the resistance vessels and by their prevailing transmural pressure, which was largely equal in NCR and SHR. Therefore, the 35 per cent higher TPR after pithing, compared with $\mathrm{NCR}(\mathrm{p}<0.01)$, indicates a structural narrowing of the SHR resistance vessels, in agreement with previous findings in artificially perfused, maximally dilated systemic vascular bed in SHR and NCR (Folkow et al. 1970). Further hemodynamic analyses indicate an increase in wall/lumen ratio confined to the precapillary resistance vessels and mainly due to a rapidly established media thickening (Folkow et al. 1973, 1974). Due to this precapillary "structural autoregulation" in SHR both excitatory and inhibitory influences result in exaggerated precapillary luminal changes for given changes in smooth muscle activity. An important positive feedback interaction is thus created between functional excitatory and structural influences so that a higher resistance may be maintained in SHR by the same neurogenic activity as in NCR (cf. Folkow 1975). However, it also implies exaggerated resistance and pressure reductions in SHR compared with NCR when, as in this particular case, all neurohormonal excitatory influences are suddenly eliminated (Fig. 1).

Further, the present results show a relatively more pronounced CO reduction in SHR than in NCR upon complete denervation. In this situation cardiac performance is mainly determined by the myocardial "heterometric and homeometric autoregulation" (cf. Sarnoff and Mitchell 1962). Since MAP was largely equal in NCR and SHR after pithing, the diastolic filling pressure will primarely determine $\mathrm{CO}$ since inherent heart rates proved to be largely equal in NCR and SHR in this case. Thus stroke volume was about 35 per cent lower in SHR than in NCR after pithing, which may in part be explained by a relatively more pronounced interference with the SHR myocardial blood supply as a result of the marked fall in pressure head. More important is probably the fact that SHR left ventricles display 
a lower stroke volume for a given enddiastolic pressure compared with NCR. The reason is that the average myocardial stretch becomes reduced largely in proportion to the left ventricular hypertrophy, shifting the Frank-Starling curve for SHR to the right in the physiological range of filling pressures (Hallbäck, Isaksson and Noresson 1975). Consequently, the sympathetic control of the low-pressure capacitance compartments might become increasingly important along with the development of SHR hypertension, being here needed to ensure a proper filling of the gradually less compliant left ventricle.

In summary, the hemodynamic pattern in SHR and NCR after complete cardiovascular denervation, in the prevailing situation associated with maximal systemic vasodilatation, is in SHR characterized by a 35 per cent higher TPR and a proportionally lower CO, and stroke volume, compared with equally treated NCR. These opposite changes in TPR and $\mathrm{CO}$ after denervation lead to about equal MAP levels in SHR and NCR. Both these changes are consequences mainly of the rapidly established structural adaptation of the cardiovascular high-pressure compartments occurring in hypertension and involving not only the left ventricle and systemic arteries but also the precapillary resistance vessels.

This study was partly supported by grants from the Swedish Medical Research Council (No B74-14X-16$10 \mathrm{C}$ ), from the Medical Faculty, University of Göteborg and from Svenska Nationalföreningen mot Hjärtoch Lungsjukdomar. AB Hässle generously covered part of the expenses for a technician.

\section{References}

ClaRK, D. W. J., Effects of immunosympathectomy on development of high blood pressure in genetically hypertensive rats. Circulat. Res. 1971. 28, 330-336.

Folkow, B., Central neuro-hormonal mechanisms in spontaneously hypertensive rats as compared with human essential hypertension. Clin. Sci. and Mol. Med. 1975. In press.

Folkow, B., M. Hallbäck, Y. Lundgren and L. WeIss, Background of increased flow resistance and vascular reactivity in spontaneously hypertensive rats. Acta physiol. scand. 1970. 80. 93-106.

Folkow, B., M. Hallbäck, Y. LundGren and L. Weiss, The effects of "immunosympathectomy" on blood pressure and vascular "reactivity" in normal and spontaneously hypertensive rats. Acta physiol. scand. 1972. 84. 512-523.

Folkow, B., M. Hallbäck, Y. Lundgren, R. Sivertsson and L. Weiss, The importance of adaptive changes in vascular design for establishment of primary hypertension studied in man and in SHR. Circulat. Res. 1973. 32-33. Suppl. I. 2-13.

Folkow, B., M. Hallbäck, Y. Lundgren, L. Weiss, I. Albrecht and S. Julius, Analysis of design and "reactivity" of series-coupled vascular sections in spontaneously hypertensive rats (SHR). Acta physiol. scand. 1974. 90. 654-656.

Hallbäck, M. and B. Folkow, Cardiovascular responses to acute mental "stress" in spontaneously hypertensive rats. Acta physiol. scand. 1974. 90. 684-698.

HALLB̈̈CK, M., Consequences of social isolation on blood pressure, cardiovascular reactivity and design in spontaneously hypertensive rats. Acta physiol. scand. 1975. 93. 455-465.

HALlbäCK, M., O. IsaKsson and E. Noresson, Consequences of myocardial structural adaptation on left ventricular compliance and the Frank-Starling relationship in spontaneously hypertensive rats. Acta physiol. scand. 1975. 94. 259-270.

IrIUCHIIMA, J., Cardiac output and total peripheral resistance in spontaneously hypertensive rats. Jap. Heart J. 1973. 14. 267-272.

Nosaka, S., Y. YAmoRi, T. OHTA and K. OKamoto, Neural fraction of peripheral vascular resistance and vascular reactivity in the spontaneously hypertensive rat. In Spontaneous Hypertension. 1972. Ed. K. Okamoto. Igaku Shoin Ltd. Tokyo.

Oxamoto, K., Spontaneous hypertension in rats. Int. Rev. exp. Path. 1969. 7. 227-270. 
SARnoff, S. J. and J. H. Mitchell, The control of the function of the heart. In Handbook of physiology. 1962. 1. 489-532. Ed. W. F. Hamilton and P. Dow. Amer. Physiol. Soc. Washington D.C.

Shibayama, F., S. Mizogami and H. Sokabe, Cardiovascular reactivity in hypertensive rats. Jap. Heart J. 1971. 12. 68-78.

SMIRK, H., The neurogenically maintained component in hypertension. Circulat. Res. 1970. 26-27. Suppl. II. 22-63.

WeIss, L., Long-term treatment with antihypertensive drugs in spontaneously hypertensive rats (SHR). Effects on blood pressure, survival rate and cardiovascular design. Acta physiol. scand. 1974. 91. 393408.

Weiss, L., Y. LundGReN and B. Folkow, Effects of prolonged treatment with adrenergic $\beta$-receptor antagonists on blood pressure, cardiovascular design and reactivity in spontaneously hypertensive rats (SHR). Acta physiol. scand. 1974. 91. 447-457. 